\title{
Geographic and Specialty Distribution of US Physicians Trained to Treat Opioid Use Disorder
}

Roger A. Rosenblatt, MD, MPH, $M F R^{1 \dagger}$

C. Holly A. Andrilla, MS

Mary Catlin, BSN, MPH ${ }^{1,2}$

Eric H. Larson, $P b D^{1}$

'WWAMI Rural Health Research Center, Department of Family Medicine, University of Washington School of Medicine, Seattle, Washington

${ }^{2}$ Group Health Cooperative of Puget Sound, Seattle, Washington

†Died December 12, 2014

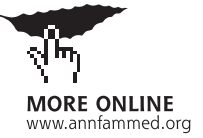

Conflicts of interest: Catlin reports consultancies for University Researcb Co, LLC.

\section{CORRESPONDING AUTHOR}

C. Holly A. Andrilla, MS WWAMI Rural Health Research Center Department of Family Medicine

University of Washington

Box 354696

Seattle, WA 98195-4696

hollya@uw.edu

\begin{abstract}
PURPOSE The United States is experiencing an epidemic of opioid-related deaths driven by excessive prescribing of opioids, misuse of prescription drugs, and increased use of heroin. Buprenorphine-naloxone is an effective treatment for opioid use disorder and can be provided in office-based settings, but this treatment is unavailable to many patients who could benefit. We sought to describe the geographic distribution and specialties of physicians obtaining waivers from the Drug Enforcement Administration (DEA) to prescribe buprenorphine-naloxone to treat opioid use disorder and to identify potential shortages of physicians.
\end{abstract}

METHODS We linked physicians authorized to prescribe buprenorphine on the July 2012 DEA Drug Addiction Treatment Act (DATA) Waived Physician List to the American Medical Association Physician Masterfile to determine their age, specialty, rural-urban status, and location. We then mapped the location of these physicians and determined their supply for all US counties.

RESULTS Sixteen percent of psychiatrists had received a DEA DATA waiver (41.6\% of all physicians with waivers) but practiced primarily in urban areas. Only $3.0 \%$ of primary care physicians, the largest group of physicians in rural America, had received waivers. Most US counties therefore had no physicians who had obtained waivers to prescribe buprenorphine-naloxone, resulting in more than 30 million persons who were living in counties without access to buprenorphine treatment.

CONCLUSIONS In the United States opioid use and related unintentional lethal overdoses continue to rise, particularly in rural areas. Increasing access to office-based treatment of opioid use disorder-particularly in rural America-is a promising strategy to address rising rates of opioid use disorder and unintentional lethal overdoses.

Ann Fam Med 2015;13:23-26. doi: 10.1370/afm.1735.

\section{INTRODUCTION}

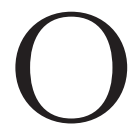
$\mathrm{f}$ the 30 leading diseases and injuries in the United States, druguse disorders have accounted for the greatest increase in deaths and years of life lost between 1990 and 2010. ${ }^{1}$ The largest portion of these deaths results from the ingestion of prescription and illicit opioids, ${ }^{2,3}$ exceeding the number of people dying in car accidents. ${ }^{4}$

Addressing this epidemic will require a new approach to the treatment of problems related to opioid use. To expand treatment options beyond opioid treatment programs, the US Congress passed the Drug Addiction Treatment Act (DATA 2000). ${ }^{5}$ This expansion of harm-reduction treatment allows office-based physicians who complete training to obtain a waiver that permits prescribing buprenorphine to treat opioid use disorder. This study examines the extent to which the population in the United States has local access to physicians who received a waiver and can provide effective harm-reduction treatment for opioid use disorder.

\section{METHODS}

This research used multiple data sources: The American Medical Association (AMA) Physician Masterfile (2012), the Drug Enforcement Administra- 
The regional distribution of physicians who can prescribe buprenorphine is striking. Figure 1 shows that physicians with waivers are concentrated on the east and west coasts, leaving wide swaths of contiguous counties in the middle of the country without any such physicians. Residents of these counties must travel long distances to receive outpatient buprenorphine treatment.

The percentage of physicians with waivers varied widely by state, from $0.6 \%$ in Nebraska to $6.8 \%$ in Vermont. The ratio of these physicians to 100,000 population varied 15 -fold by state (data available on request).

\section{DISCUSSION}

Despite the availability of office-based therapy for the treatment for opioid use disorder-and despite efforts to expand its availability-only 2.2\% of American physicians have obtained the waivers required to prescribe buprenorphine to treat opioid use disorders. We found that $90.4 \%$ of these physicians were practicing in urban counties, leaving the majority of US counties (53.4\%) — most of them rural—with no physician with a DEA DATA waiver.
The relative paucity of these physicians in rural areas is a major barrier to office-based outpatient treatment for opioid use disorder. The per capita supply of physicians with waivers in the most rural counties is one-half the supply in urban settings. Although primary care physicians are the predominant providers of health care in rural America, very low percentages of family physicians and general internists (3.0\%) have obtained a DEA DATA waiver. Psychiatrists, who comprise more than $40 \%$ of the physicians with waivers, are rare or nonexistent in rural America. ${ }^{7}$

Additionally, obtaining a waiver to prescribe buprenorphine does not ensure that physicians will incorporate this modality into their treatment of opioid use disorder. The presence of a physician who has obtained a waiver does not necessarily mean that buprenorphine treatment is available. ${ }^{8-10}$ In the only national study of this issue, the average physician with a waiver was currently treating 26 patients (mean) with buprenorphine, ${ }^{11}$ and $25 \%$ of the physicians had not treated any patients since obtaining their waiver. Other studies found that those physicians actually prescribing buprenorphine were treating a relatively small number of patients. ${ }^{12,13}$

\section{Figure 1. US counties with physicians with waivers to prescribe buprenorphine.}

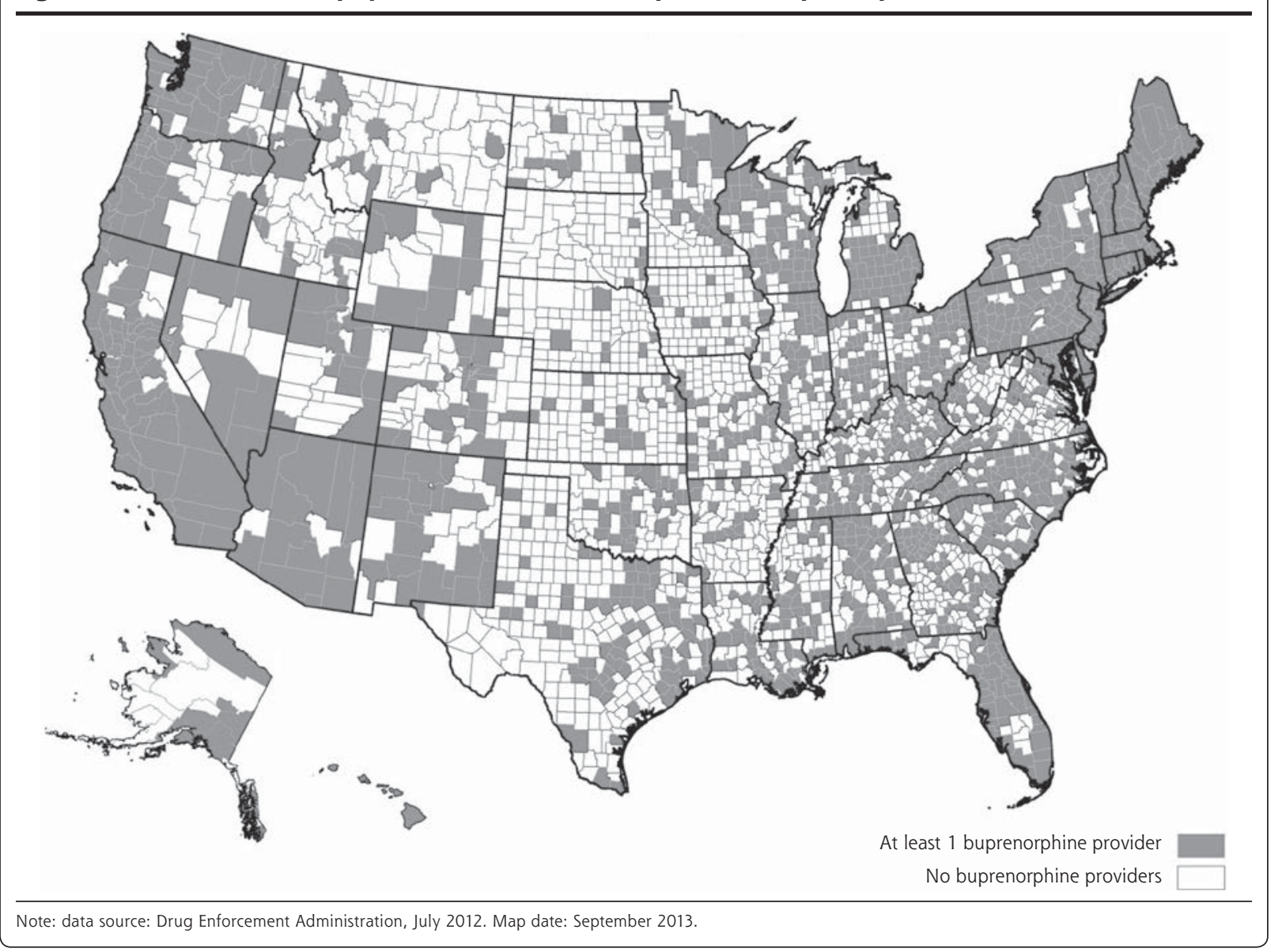


The low rate of young physicians with waivers suggests that they are not being trained during residency in the treatment of opioid use disorders. Obtaining a waiver for buprenorphine and mastering some of the nuances of treatment during residency could increase the likelihood that these future practitioners would identify and treat opioid use disorder.

The complexity and stigma surrounding officebased treatment of patients with opioid use disorder dissuade many physicians from adopting buprenorphine as a treatment option. ${ }^{14}$ Barriers to providing buprenorphine therapy include a lack of institutional support, inadequate support from nursing and office staff, a lack of mental health practitioners, payment issues, and opposition from practice partners. ${ }^{12,14}$ Coordinated efforts to train and support teams of clinicians in specific rural practices, including mental health clinicians comfortable with on-site harm-reduction therapies, and reimbursing this care at a reasonable amount would be promising first steps to addressing these barriers.

This study is limited by several factors. First, although we had access to information about the amount of opioids prescribed in all 50 states, there were no data on the number of patients who would meet the criteria for addiction or benefit from buprenorphine therapy. Thus it is possible that some counties that had one or more physicians with waivers may have a greater need for additional buprenorphine-prescribing physicians than counties with physicians with no waivers at all. Second, it was not possible using the DEA DATA Waived Physician List to determine whether buprenorphine treatment was available for patients with opioid use disorder in the county where they live, as obtaining a waiver does not guarantee that the physicians will add this treatment option to their practices.

The distribution of physicians with DEA DATA waivers across US counties leaves rural counties with little or no access to office-based opioid use disorder treatment. Rural counties, especially more isolated ones, have a substantially lower supply of buprenorphine-prescribing physicians per 100,000 residents. Office-based treatment of opioid use disorder with buprenorphine has been effective in expanding the options available to patients and physicians. Increasing the number of physicians with DEA DATA waivers could improve access to treatment for patients — particularly in rural America_-and is a promising strategy to address the rising rates of opioid use disorder and lethal unintentional overdoses.

To read or post commentaries in response to this article, see it online at http://www.annfammed.org/content/13/1/23.

Submitted April 4, 2014; submitted, revised, September 9, 2014; accepted September 18, 2014.
Key words: buprenorphine; opiate substitution treatment; rural health; primary health care; opiate addiction; opioid treatment programs

Funding support: This study was supported by the Federal Office of Rural Health Policy, Health Resources and Services Administration, us Department of Health and Human Services (grant \#U1CRH03712); and by the Life Sciences Discovery Fund (LSDF) of the State of Washington.

Prior presentations: Northwest Regional Rural Health Conference, March 18-20, 2014, Spokane, Washington.

Supplementary materials: Available at http://www.AnnFamMed. org/content/13/1/23/suppl/DC1/.

\section{References}

1. US Burden of Disease Collaborators. The state of US health, 1990-2010: burden of diseases, injuries, and risk factors. JAMA. 2013;310(6):591-608.

2. Centers for Disease Control and Prevention (CDC). Drug overdose deaths-Florida, 2003-2009. MMWR Morb Mortal Wkly Rep. 2011;60(26):869-872.

3. National Center for Health Statistics. Health, United States, 2012: With Special Feature on Emergency Care. Washington, DC: US Department of Health and Human Services; 2013.

4. Paulozzi LJ. Prescription drug overdoses: a review. J Safety Res. 2012:43(4):283-289.

5. Drug Addiction Treatment Act of 2000. Public Law 106-310. Page 114 Stat. 1101. http://buprenorphine.samhsa.gov/fulllaw.html. Accessed Jan 30, 2014.

6. US Department of Agriculture Economic Research Service. Urban Influence Codes. http://www.ers.usda.gov/data-products/urbaninfluence-codes.aspx. UgJ5jZK86So. Accessed Jan 30, 2014.

7. Ellis AR, Konrad TR, Thomas KC, Morrissey JP. County-level estimates of mental health professional supply in the United States. Psychiatr Serv. 2009;60(10):1315-1322.

8. American Board of Addiction Medicine. Congratulations to the 2012 diplomates of the American Board of Addiction Medicine. http://www.abam.net/exam-results/. Accessed Jan 30, 2014.

9. American Board of Medical Specialties. Specialties and subspecialties. http://www.abms.org/Who_We_Help/Physicians/specialties. aspx. Accessed Jan 30, 2014.

10. American College of Obstetricians and Gynecologists. Opioid abuse during pregnancy spurs medical treatment guidance. 2012; http:// www.acog.org/About_ACOG/News_Room/News_Releases/2012/ Opioid_Abuse_During_Pregnancy_Spurs_Medical_Treatment_Guidance. Accessed Jan 30, 2014.

11. Arfken $C L$, Johanson $C E$, di Menza S, Schuster CR. Expanding treatment capacity for opioid dependence with office-based treatment with buprenorphine: National surveys of physicians. J Subst Abuse Treat. 2010;39(2):96-104.

12. Hutchinson E, Catlin M, Andrilla CHA, Baldwin LM, Rosenblatt RA. Barriers to primary care physicians prescribing buprenorphine. Ann Fam Med. 2014;12(2):128-133.

13. Quest TL, Merrill JO, Roll J, Saxon AJ, Rosenblatt RA. Buprenorphine therapy for opioid addiction in rural Washington: the experience of the early adopters. J Opioid Manag. 2012;8(1):29-38.

14. Walley AY, Alperen JK, Cheng DM, et al. Office-based management of opioid dependence with buprenorphine: clinical practices and barriers. J Gen Intern Med. 2008;23(9):1393-1398.

15. American Society of Addiction Medicine. Membership. http://www. asam.org/membership. Accessed Jan 30, 2014.

16. CASAColumbia. Addiction medicine: closing the gap between science and practice. 2012; http://www.casacolumbia.org/addictionresearch/reports/addiction-medicine. Accessed Jan 29, 2014. 